\title{
When will learning style go out of style?
}

\author{
Geoff Norman
}

Received: 19 January 2009/Accepted: 19 January 2009/Published online: 3 February 2009

(C) Springer Science+Business Media B.V. 2009

This issue contains a beautifully designed and executed study looking at learning style and its potential interaction with learning. Cook (1) administered the Index of Learning Styles to 123 residents, which classified the participants on four dimensions: active-reflective, visual-verbal, sensing-intuitive, and sequential-global. This inventory has some similarity to the more popular Kolb inventory, which has a concrete-abstract dimension analogous to the sensing-intuitive axis. The visual-verbal axis, while not present in other inventories, is actually the one that, in my experience at least, people usually volunteer when they think about learning styles, i.e., "I'm a verbal learner". And I'll have much more to say about this.

They then did a within-subject design, where all residents saw two instructional modules in a problem-based format, and two in a didactic content-first format. Everything was crossed over. Residents then did a knowledge post test with multiple choice questions. According to the theory, "sensing" residents should do better on a case-based approach and "intuitive" residents on a didactic approach. At the end of the day, there was no difference in scores between the conditions where sensing style was matched to problembased and intuitive to didactic, and the mismatched condition. Further, there was no relationship between sensing-intuitive and preference for one format or the other.

Now, this is one study, and there are a zillion potential problems. Maybe the instrument was not reliable or valid enough. Maybe the hypothesis about a link between sensingintuitive and problem first-content first is wrong. Maybe the modules did not do a very good job of exploiting the PBL format. Maybe the multiple choice test did not really get at the important learning. Maybe, maybe....

But there are two good reasons to discount all these worries. First, whatever one thinks of the results, the study did one thing very well. Instead of simply administering a learning style measure and finding some individual differences, then saying, "Oh look, people have different learning styles. We should tailor instruction to these learning styles", they actually did it. After all, the whole point of assessing learning style is so that instructional materials and teachers can take this into account in order to improve effectiveness of

G. Norman $(\bowtie)$

McMaster University, 1200 Main Street W., Hamilton, ON L8N3Z5, Canada

e-mail: norman@mcmaster.ca 
instruction. The basic idea goes back to Cronbach, and the idea that we should look at what instructional strategy works best for whom, so-called "aptitude-treatment interactions" (Cronbach 1957; Norman 2002). Without this application, learning style is about as useful as a horoscope.

The second reason is that Cook's findings are pretty well consistent with all the other studies of that kind. Cook has, in fact, reported one other study using the same basic match-mismatch design (Cook et al. 2007), which again showed nothing. He appears to have got into the learning style game with a systematic review that he reported in 2005 , which appeared to show some evidence of an interaction between active-passive learning style and interactive learning. However, the studies in health sciences that he examined appear to pretty uniformly show no effect, although there appeared to be some positive effects in other literature. It may be that the kind of highly motivated, high performing students who are in medical programs are also very adaptive to different instructional modes, as Cook et al. (2007) mentions. Indeed, this appears to be an accepted assumption of the "learning strategy" literature, whose roots are more in Europe. One of the most popular learning strategy measures, by Entwistle et al. (2000), specifically identifies strategic learning, adaptable to the situation.

Other systematic reviews are hard to find, but one of the most comprehensive looks at the whole field is a web-based document of 170 pages (Coffield et al. 2004). The report addressed issues such as reliability and validity. When it comes to the specific issue of relevance for instruction, their conclusions regarding two of the most popular learning style measures are:

\section{Myers-Briggs}

"Despite the enormous commercial success of the MBTI, the research evidence to support it - both as a valid measurement of style and as an aid to pedagogy-is inconclusive, at best. The extent to which the MBTI has been accepted as part of the normal arsenal of measurements has had the unfortunate result that some of the analytical and empirical work done with it is uncritical and unreflective." (p. 51)

\section{Kolb LSI}

"How is one to make sense of such conflicting evidence, based as it is on rather small samples? Fortunately, there are two reviews of the literature which provide a little help. Cavanagh and Coffin evaluated the literature on 'matching' and found 'relatively little empirical work to indicate the exact nature and magnitude of the change that can be expected in a student's learning.' Crucially, they concluded that little is known about the interaction of learning styles with organizational and resource issues." (p. 68)

Why, then, does learning style appear to have such universal appeal? There must be something to it. After all, there are large individual differences in things such as visual and verbal ability that are well documented by IQ subtests. Doesn't this mean we should worry about ensuring that our instruction accommodates both visual and verbal learners. Well, in a word, "No!" Not in the context of self-declared visual and verbal learners, at least.

Richard Mayer, who deserves a Nobel Prize in educational research for his insightful research, has recently done a brilliant job of teasing this one apart. He and his colleagues reasoned that the notion of visual and verbal learners could be operationalized in at least three different ways:

1. The individual thinks of themselves as visual or verbal learners. 
2. The individual is given a choice between learning materials that are visual or verbal, and prefers one or the other.

3. The individuals scores higher on a visual IQ (mental rotations) or verbal IQ (vocabulary) test.

In a first study (Mayer and Massa 2003), they administered 14 different cognitive tests covering preferences, styles, aptitudes and achievements in visual and verbal domains, and showed that the measures clearly separated into four factors that they labeled cognitive style (visualizer-verbalizer), learning preferences, general ability and spatial ability. They found no relation between visual or verbal learning style, visual or verbal preference, and spatial ability. In the details, the correlation between self rated spatial versus verbal ability and self-rated visual-verbal learning style was only 0.31 .

A second study then matched the three classes of measures (visual-verbal spatial ability, learning style and learning preference) with instructional materials, like the Cook design above. Only one interaction with the 18 subtests was significant, between self-rated visual versus verbal ability and performance, and this accounted for $8 \%$ of the variance. However, none of the learning style or learning preference measures accounted for more than $2 \%$ of the variance and none were significant. A second study using a more general population came to the same conclusion.

In short, while learning style has universal appeal, it has very little to do with learning. As Clark and Mayer (2003) said a few years ago:

"While various individual differences such as learning styles have received the attention of the learning community, research has proven that the learner's prior knowledge exerts the most influence on learning". (p. 27)

Or, as the authors of the British report state in their concluding chapter:

"Moreover, the status of research in this field is not helped by the overblown claims of some of the developers and their enthusiastic devotees. For example, Carbo, the director of the National Reading Styles Institute in the US, claimed that when staff were trained for 4 or 5 days in 'matching' techniques, 'very often the results have been phenomenal, not just significant. We've had some gains of ten times as high as students were achieving before' (quoted by O'Neil 1990, 7). Rigorously conducted research, as we saw earlier, has experienced difficulty in establishing that matching produced significant, never mind phenomenal, gains". (p. 137)

The time is long overdue for learning style to go out of style.

\section{References}

Clark, R. C., \& Mayer, R. E. (2003). E-learning and the science of instruction. San Francisco: Pfeiffer.

Coffield, F., Moselely, D., Hall, E., \& Eccleston, K. (2004). Learning styles and pedagogy in post-16 learning: a systematic and critical review. London: Learning and Skills Research Centre.

Cook, D. A. (2002). Learning and cognitive styles in web-based learning: theory, evidence and application. Academic Medicine, 80, 266-278.

Cook, D. A., Gelula, M. H., Dupras, D. M., \& Schwartz, A. (2007). Instructional methods and cognitive and learning styles in web-based learning: report of two randomized trials. Medical Education, 41, 897905.

Cronbach, L. (1957). The two disciplines of scientific psychology. American Psychologist, 12, 671-684.

Entwistle, N., Tait, H., \& McCune, V. (2000). Patterns of response to an approaches to studying inventory across contrasting groups and contexts. European Journal of the Psychology of Education, 15, 38. 
Massa, L. J., \& Mayer, R. E. (2006). Testing the ATI hypothesis: should multimedia instruction accommodate visualizer-verbalizer cognitive style? Learning and Individual Difference, 16, 321-335.

Mayer, R., \& Massa, L. J. (2003). Three faces of visual and verbal learners: cognitive ability, cognitive style and learning preference. Journal of Educational Psychology, 95, 833-846.

Norman, G. R. (2002). What does 'two disciplines of scientific psychology' say to medical education. Advances in Health Sciences Education, 30, 116-127. 